\title{
Magnetic hyaluronate hydrogels: preparation and characterization
}

\author{
Ildikó Y. Tóth ${ }^{{ }^{*}}$, Gábor Veress ${ }^{\text {a }}$, Márta Szekeres a, Erzsébet Illés ${ }^{\text {a }}$, Etelka Tombácz ${ }^{\mathrm{a}^{*}}$ \\ a Department of Physical Chemistry and Materials Science, University of Szeged, Aradi Vt. 1, \\ H-6720 Szeged, Hungary \\ *Corresponding authors: Ildikó Y. Tóth (+3662544212, Ildiko.Toth@chem.u-szeged.hu) and \\ E. Tombácz (+3662544212, tombacz@chem.u-szeged.hu)
}

\author{
Highlights \\ * Novel hyaluronate(HyA)-based biocompatible magnetic hydrogels were prepared. \\ * Chondroitin-sulfate-A coating is needed to disperse magnetite particles in HyA-gel. \\ * Rheological behaviour of hydrogels was independent of the magnetite content $(<2 \mathrm{~g} / \mathrm{L})$. \\ * Gels remained in stable and homogeneously dispersed state even after 90 days storage. \\ * Magnetic HyA-gels are promising candidates for use as intra-articular injection.
}

\begin{abstract}
A novel soft way of hyaluronate (HyA) based magnetic hydrogel preparation was revealed. Magnetite nanoparticles (MNPs) were prepared by co-precipitation. Since the naked MNPs cannot be dispersed homogenously in HyA-gel, their surface was modified with natural and biocompatible chondroitin-sulfate-A (CSA) to obtain CSA-coated MNPs (CSA@MNPs). The aggregation state of MNPs and that loaded with increasing amount of CSA up to $1 \mathrm{mmol} / \mathrm{g}$ was measured by dynamic light scattering at $\mathrm{pH} \sim 6$. Only CSA@ MNP with $\geq 0.2 \mathrm{mmol} / \mathrm{g}$ CSA content was suitable for magnetic HyA-gel preparation. Rheological studies showed that the presence of CSA@MNP with up to $2 \mathrm{~g} / \mathrm{L}$ did not affect the hydrogel's rheological behaviour significantly. The results suggest that the HyA-based magnetic hydrogels may be promising formulations for future biomedical applications, e.g. as intra-articular injections in the treatment of osteoarthritis.
\end{abstract}

Keywords: magnetite, chondroitin-sulfate-A, hyaluronate, magnetic hydrogels, surface modification, intra-articular injection

\section{Introduction}

Hydrogels are in the focus of scientific interest because of their tuneable mechanical, chemical and biocompatible properties $[1,2]$. These materials have been widely used in tissue engineering and drug delivery [1,3-5]. Magnetic hydrogels have also been produced by filling hydrogels with magnetic particles (e.g. maghemite, magnetite, cobalt-ferrite) [1], this procedure makes them more suitable for certain biomedical applications, such as drug delivery $[1,6,7]$, enzyme immobilization [1,8-10] or cancer therapy by the combination of controlled drug release and magnetic hyperthermia [1,11]. Magnetic hydrogels have been prepared by three, fundamentally different methods: blending, in situ precipitation and grafting-onto methods [1]. Innumerable magnetic hydrogels have been synthesized, e.g. superparamagnetic magnetite nanoparticles (MNPs) in kappa-carrageenan nanospheres [12], in situ synthesized MNPs in chitosan hydrogel [13] and magnetic hydrogel of chitosan and MNPs for a potential cancer treatment [14]. Some hyaluronate (HyA) based magnetic hydrogels have been also prepared, e.g. hybrid magnetic hydrogels for controlled drug-delivery prepared from (3aminopropyl)trimethoxysilane-functionalized magnetite or cobalt-ferrite bound chemically to HyA by N-hydroxysuccinimide and N-(3-dimethylaminopropyl)-Nethylcarbodiimidehydrochloride [15]. Injectable in situ forming hydrogel has been synthesized 
from oleic acid-coated iron oxide nanoparticles dispersed in toluene and hyaluronic acid modified with hydrazide and thiol groups (HA-hy-SH) for MRI contrast agent [16]. The giant HyA molecules flocculate MNPs and loose aggregates are formed, which can be prevented only by the pre-modification of either the MNP's surface $[15,17]$ or the chemical structure of HyA [18] or by the combination of the previous two [16,19]. Usually harmful chemicals were used during these preparations. In our laboratory, several types of core-shell magnetite nanoparticles have been produced [20-22] in the absence of risky chemicals by using poly(acrylic acid) (PAA) [23], poly(acrylic acid-co-maleic acid) (PAM) [24] and chondroitin-sulfate-A (CSA) [25] as coating agents to modify the MNP surface.

The osteoarthritis (also called degenerative joint disease) is a common form of arthritis, which causes health problems for millions of people [26]. There are many reasons potentially responsible for the osteoarthritis, such as genetic factors, increased stress (i.e., hard physical work, sport, overweight) and decreased viscoelasticity of the intra-articular fluid. The latter can be caused by the reduced amount of hyaluronate (HyA) in the synovial fluid [27]. The supplement of synovial fluid by hyaluronate-containing intra-articular injection is a common treatment for osteoarthritis [26-30]. The typical composition of these gels (for example Hyalgan, Ostenil-Tendon, SportVis, Synvisc, Synocrom) is an isotonic solution (150 mM NaCl, pH $\sim 7.3$ adjusted by buffer) containing $1 \%$ of sodium hyaluronate. There are several problems with this treatment, for example the rapid enzymatic degradation of HyA within the joints [31], the pain and the risk of infection during the injection procedure. Furthermore, during movement and under the weight of the patient's body, the synovial fluid could be squeezed outside the joints reducing the efficiency of the intra-articular treatments. Our approach is to overcome the latter defect by using magnetic hydrogel and its flowability that can be regulated by an implanted permanent magnet.

The aim of our research was to prepare HyA-based magnetic hydrogel samples in a soft way using biocompatible chemicals, which may be potentially used as an intra-articular injection in the future. The chemical structures of hyaluronate and biocompatible chondroitinsulfate-A are very similar (Fig. 1), so it is presumable that the surface of CSA-coated superparamagnetic magnetite nanoparticles (CSA@MNPs) is compatible with the HyA-gel. We intend to prepare stable MNPs and CSA-coated MNPs, and to test their stability and aggregation in dilute HyA-gels. Finally, we plan to prepare HyA-based magnetic hydrogels and to test the effect of increasing CSA@MNP concentration on the rheological properties.

\section{Materials and methods}

\subsection{Materials}

The magnetite was prepared by co-precipitation [32-36]. The $\mathrm{FeCl}_{2}, \mathrm{FeCl}_{3}$ and $\mathrm{NaOH}$ for magnetite synthesis were analytical grade reagents obtained from Molar, Hungary. The precipitate was purified carefully through washing and dialysis. It was stored at $\mathrm{pH} \sim 3$ and $4{ }^{\circ} \mathrm{C}$ as stable sol. The resulting iron-oxide was identified as magnetite, based on the characteristic black colour, strong magnetism and the X-ray diffraction pattern (JCPDS database [37]). The mean diameter of the MNPs, determined by Scherrer equation and transmission electron microscopy, was $\sim 10 \mathrm{~nm}[21]$.

The chondroitin-sulfate-A (CSA) was purchased from Sigma-Aldrich as sodium-salt, and the sodium-salt of hyaluronic acid (HyA) was kindly provided by the Department of Pharmaceutical Technology (University of Szeged, Hungary). One repeating unit of CSA $(\mathrm{M}=503 \mathrm{Da})$ contains one $-\mathrm{COOH}$ and one $-\mathrm{SO}_{3} \mathrm{H}$ group (Fig. 1a) and that of $\mathrm{HyA}(\mathrm{M}=379$ Da) contains one $-\mathrm{COOH}$ group (Fig. 1b). The strongly acidic sulfate groups $\left(-\mathrm{SO}_{3}{ }^{-}\right)$in $\mathrm{CSA}$ are fully deprotonated at a wide $\mathrm{pH}$-range $[38,39]$. However, the $-\mathrm{COOH}$ groups in CSA and HyA have $\mathrm{pH}$-dependent dissociation $\left(\mathrm{pK}_{\beta \text {-glucuronic acid }}\right.$ 2.9) [40] but, even so, these groups are fully deprotonated $\left(-\mathrm{COO}^{-}\right)$at $\mathrm{pH} \sim 6.3$ applied in our experiments. The notations "CSA" and 
"HyA" are used in this article for sodium-salt regardless of the actual degree of dissociation of the carboxylic groups. The amount of CSA and HyA is expressed through the mole of repeating units, which equals to the number of dissociable - $\mathrm{COOH}$ groups.

The CSA-coated magnetite nanoparticles (CSA@MNPs) were prepared at $\mathrm{pH}=6.3 \pm 0.3$ and $10 \mathrm{mM} \mathrm{NaCl}$, the MNP-content was $20 \mathrm{~g} / \mathrm{L}$, the CSA-loading was 0.2, 0.4 and $1.0 \mathrm{mmol}$ $\mathrm{COOH} / \mathrm{g} \mathrm{MNP}$ and the adsorption time was one day. These amounts of CSA completely coat MNPs and provide the high colloidal stability of the CSA@MNP particles [25].

The HyA-gel was prepared by the dissolution of hyaluronic acid in ultra pure water under one day long continuous stirring. The HyA-content of the stock-gel was $11 \mathrm{mg} / \mathrm{mL}$ and the $\mathrm{pH}$ was $\sim 5.8$. Thereafter, the calculated amounts of the naked MNPs or CSA@ MNPs at 0.4 $\mathrm{mmol} / \mathrm{g}$ CSA-loading were added to $9 \mathrm{~mL}$ of the previously prepared HyA-gel under vigorous magnetic stirring and the total volume was adjusted to $10 \mathrm{~mL}$ using $10 \mathrm{mM} \mathrm{NaCl}$ solutions $(\mathrm{pH}=6.3 \pm 0.3)$. Stirring was continued for five minutes. The final HyA-content of the hydrogels was $10 \mathrm{mg} / \mathrm{mL}$ similar to that in commercial HyA-based intra-articular injections (for example Synocrom). The magnetite-content of the magnetic hydrogels was $2.0 \mathrm{~g} / \mathrm{L}$ for the naked MNPs and $0.0,0.2$ and $2.0 \mathrm{~g} / \mathrm{L}$ for CSA@MNPs at $\mathrm{pH} \sim 6.0$ and $\sim 1 \mathrm{mM} \mathrm{NaCl}$. The HyA-gels were stored in closed vials at $4{ }^{\circ} \mathrm{C}$.

$\mathrm{NaCl}, \mathrm{HCl}$ and $\mathrm{NaOH}$, analytical grade products of Molar (Hungary), were used to adjust the $\mathrm{pH}$ and salt concentration in all experiments. Ultra pure water from a Milli-Q RG water purification system (Millipore) was used. All measurements were performed at $25 \pm 0.1$ ${ }^{\circ} \mathrm{C}$.

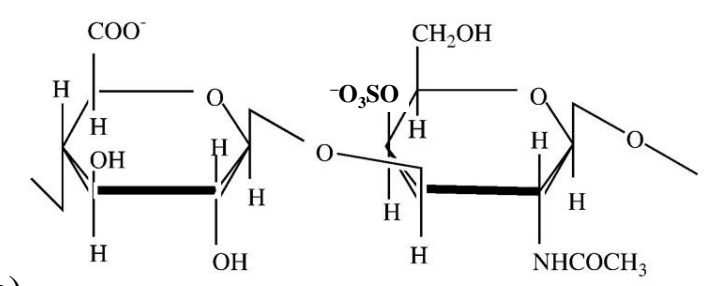

b)

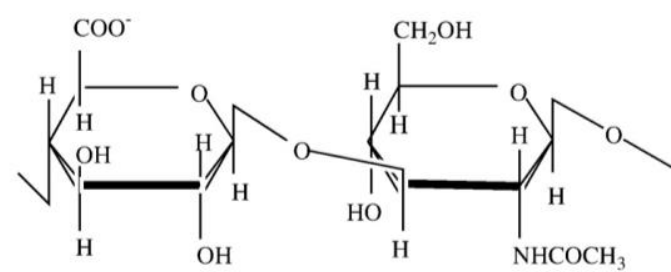

Fig. 1. The repeating units of (a) chondroitin-sulfate-A (CSA) and (b) hyaluronic acid (HyA) [41].

\subsection{Particle Size Determination}

For characterization of the aggregation state of magnetic nanoparticles in diluted HyAsystems, the $\mathrm{Z}$ average particle hydrodynamic diameter of bare magnetite and of CSA-coated nanoparticles was determined at $25 \pm 0.1^{\circ} \mathrm{C}$ using dynamic light scattering (DLS) method, an apparatus Nano ZS (Malvern) with a $4 \mathrm{~mW} \mathrm{He}-\mathrm{Ne}$ laser source $(\lambda=633 \mathrm{~nm})$ operating in backscattering mode at an angle of $173^{\circ}$. The dispersions contained $100 \mathrm{mg} / \mathrm{L}$ of magnetite to get an optimal intensity of $\sim 10^{5}$ counts per second. Prior to the measurements, the samples were homogenized in an ultrasonic bath for $10 \mathrm{~s}$, after which 2 min relaxation was allowed. For evaluation, second- or third-order cumulant fit of the autocorrelation functions was used, depending on the degree of polydispersity. The influence of the added HyA amounts (0.0-2.5 mmol HyA/g magnetite) was determined at $\mathrm{pH}=6.3 \pm 0.3$ and $10 \mathrm{mM} \mathrm{NaCl}$ in case of MNPs and CSA@MNPs. The CSA-loadings were 0.2, 0.4, and $1.0 \mathrm{mmol} \mathrm{CSA/g}$ magnetite [25].

\subsection{Electrokinetic potential measurements}

Electrophoretic mobilities of the naked magnetite and CSA@MNP dispersions were measured at $25 \pm 0.1{ }^{\circ} \mathrm{C}$ in a Nano ZS (Malvern) apparatus using disposable zeta cells (DTS 1060). The zeta-standard of Malvern $(-55 \pm 5 \mathrm{mV})$ was used for calibration. The Smoluchowski equation was applied to convert electrophoretic mobilities to electrokinetic potential values. The accuracy of the measurements was $\pm 5 \mathrm{mV}$. The samples were identical to those in the DLS experiments. 


\subsection{Rheological measurements}

The flow properties of the prepared blank HyA- and magnetic HyA-gels (Section 2.1.) were characterized systematically. The rheological measurements of three-days old samples were carried out with a Physica MCR101 rheometer (Anton Paar, Austria) and a plate-plate measuring device (diameter: $5 \mathrm{~cm}$ ) at $25 \pm 0.1^{\circ} \mathrm{C}$.

Flow curves of the different samples were determined. The shear rate was increased from 0.5 to $50 \mathrm{~s}^{-1}$ (upward curve), and then it was decreased from 50 to $0.5 \mathrm{~s}^{-1}$ (downward curve) in the CR mode. The shearing time in both segments was $60 \mathrm{~s}$. The downward curves over the plastic flow range (above shear rate $\sim 20 \mathrm{~s}^{-1}$ ) were evaluated according to the Binghammodel given by Eq. (1):

$$
\tau=\tau_{\mathrm{B}}+\eta_{\mathrm{pl}} \cdot \mathrm{d} \gamma / \mathrm{dt}
$$

where $\tau$ is the shear stress, $\tau_{\mathrm{B}}$ is the Bingham yield value, $\eta_{\mathrm{pl}}$ the plastic viscosity and $\mathrm{d} \gamma / \mathrm{dt}$ the shear rate $[42,43])$.

The creep tests were performed to determine the viscoelastic behavior under static condition. A constant stress ( 0.1 and 5.0 Pa) was applied for $60 \mathrm{~s}$ and the resulting deformation was measured (creep), then stress was released and the deformation was measured again for 60 $\mathrm{s}$ (recovery).

The dynamic tests of viscoelasticity were also conducted in forced oscillation measurements in the range of stress from 0.1 to $10 \mathrm{~Pa}$ at $1 \mathrm{~Hz}$ and of frequency from 0.1 to 10 $\mathrm{Hz}$ at $1 \mathrm{~Pa}$. Both storage modulus (G') and loss modulus (G') were analyzed.

\section{Results and discussion}

\subsection{Electrokinetic potential, particle size and aggregation}

The changes in the $\mathrm{Z}$ average particle diameter and the electrokinetic potential of the naked and CSA-coated magnetite nanoparticles are plotted as a function of HyA-addition in Fig. 2. Photos in Fig. 3 show the change in colloidal stability of MNP and CSA@MNP at 0.4 $\mathrm{mmol} / \mathrm{g} \mathrm{CSA}$-loading as a function of HyA-addition after standing for one day.
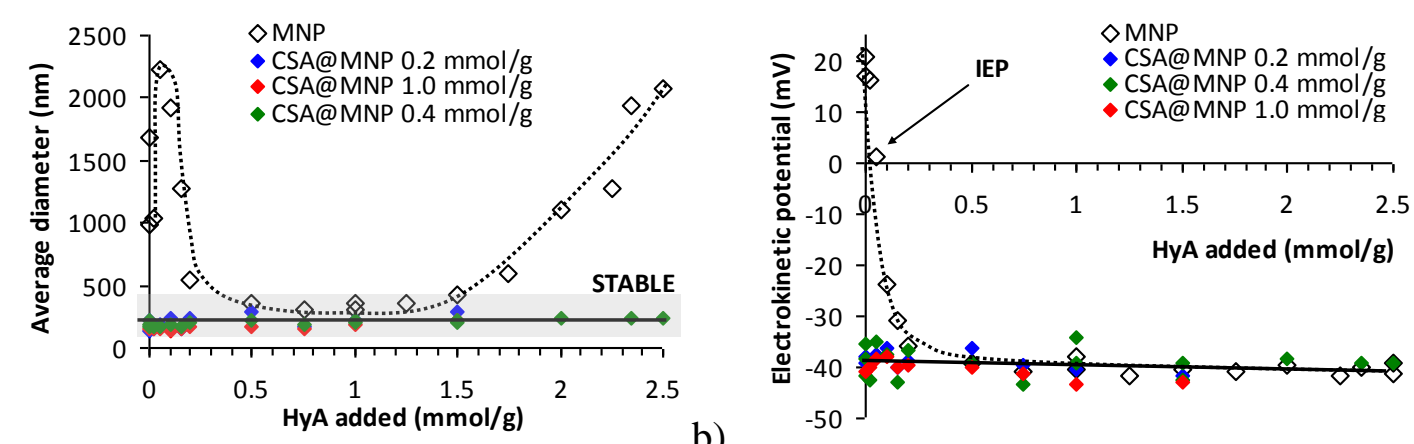

a)

Fig. 2. Effect of HyA-addition on the (a) $\mathrm{Z}$ average particle diameter and (b) electrokinetic potential of MNPs and CSA@MNPs (CSA-loadings: 0.2, 0.4 and $1.0 \mathrm{mmol} / \mathrm{g}$ ) at $\mathrm{pH} 6.3$ and $10 \mathrm{mM} \mathrm{NaCl}$, at a solid/liquid ratio of $100 \mathrm{mg} / \mathrm{L}$. (Lines are drawn as guides for the eye. The amounts of CSA and HyA are expressed as molar amounts of repeating units given in mmol.) 


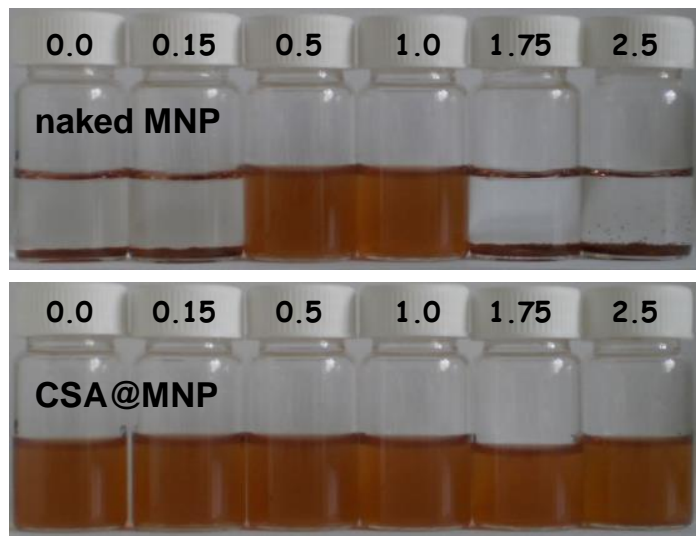

Fig. 3. Effect of increasing HyA addition (up to $2.5 \mathrm{mmol} / \mathrm{g}$, see the numbers on the vials) on the colloidal stability of the naked MNP and CSA@MNP (CSA-loading: $0.4 \mathrm{mmol} / \mathrm{g}$ ) dispersions after standing for 24 hours at $\mathrm{pH} \sim 6.3$ and $10 \mathrm{mM} \mathrm{NaCl}$, at a solid/liquid ratio of $100 \mathrm{mg} / \mathrm{L}$.

With increasing HyA-concentration, the aggregation state of the originally naked MNPs changes characteristically (see Fig. 3). At pH 6.3 and $10 \mathrm{mM} \mathrm{NaCl}$, the naked magnetite is aggregated and settled [23,24]. Although the net surface charge of MNP is positive due to the presence of $\equiv \mathrm{Fe}-\mathrm{OH}_{2}{ }^{+}$groups on the surface $[23,24,32,33,37,44-46]$, the amount of the charge is not enough to stabilize the particles electrostatically. The electrokinetic potential of the naked magnetite is $\sim+25 \mathrm{mV}$, and this sample is aggregated $(\sim 1000 \mathrm{~nm})$ (see Fig. 2). In case of trace $(<0.5 \mathrm{mmol} / \mathrm{g})$ or very large $(>1.5 \mathrm{mmol} / \mathrm{g})$ amounts of HyA, the particles settle after 24 hours. However, at intermediate HyA-concentrations $(\sim 0.5-1.5 \mathrm{mmol} / \mathrm{g})$ the magnetite dispersions are stable (middle samples in Fig. 3). The electrokinetic potential of the positive naked MNPs declines with the increase in the amount of added HyA because the negatively charged HyA adsorbed on MNPs. The charge neutralization occurs at $\sim 0.05 \mathrm{mmol} / \mathrm{g} \mathrm{HyA}$-addition, resulting in surface charge heterogeneity due to the patch-wise adsorption of HyA. This marks the isoelectric point (IEP) and the size of HyA@MNP aggregates reaches maximum $(\sim 2300 \mathrm{~nm})$. Further addition of HyA caused charge reversal and reduced the electrokinetic potential to $40 \mathrm{mV}$. The electrosteric stabilization, typical for polyelectrolytes, can be observed only in the range of $\sim 0.5-1.5 \mathrm{mmol} / \mathrm{g}$ HyA. Stabilization is accompanied by a low hydrodynamic diameter $(\sim 250 \mathrm{~nm})$. The aggregation observed at larger HyA-addition $(>1.5 \mathrm{mmol} / \mathrm{g})$ is caused by the flocculation effect of the high molecular weight HyA, so these particles do not seem to be suitable for preparation of magnetic HyA-gels.

The colloidal state of the originally stable CSA@MNPs [25] does not change with increasing HyA concentration (Fig. 3). The hydrodynamic diameters $(\sim 150 \mathrm{~nm})$ and the electrokinetic potentials $(\sim-40 \mathrm{mV})$ are independent from the CSA-loadings and the HyAaddition (Fig. 2). Thus, the CSA@MNP particles can be used to prepare magnetic HyA-gels.

\subsection{Rheological measurements of hydrogels}

The photos of the HyA-hydrogels prepared at $10 \mathrm{mg} / \mathrm{mL}$ HyA concentration are shown in Fig. 4. As it was expectable from the DLS measurements of the diluted gels (Section 3.1.), the naked MNPs can not be dispersed homogeneously in the HyA-gel; however, the CSA@MNP particles are compatible with the hydrogels forming well dispersed systems. The CSA@MNP-containing magnetic hydrogels remained stable and homogeneously dispersed even after three months of storage. 


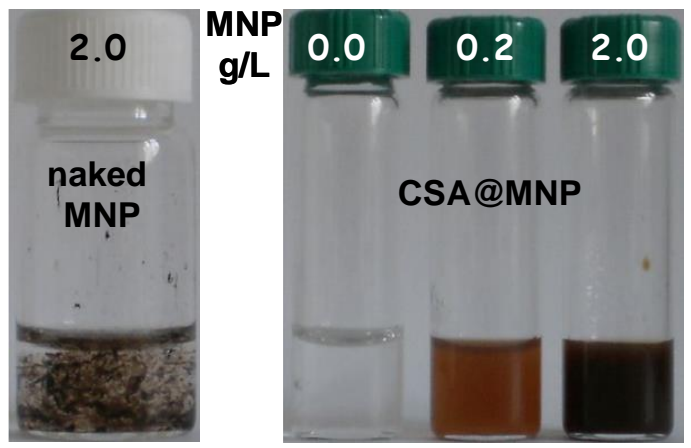

Fig. 4. HyA-gels with MNP and CSA@MNP at different magnetite contents (see on the vials) (HyA-content: 10 $\mathrm{mg} / \mathrm{mL}$, CSA-loading: $0.4 \mathrm{mmol} / \mathrm{g}, \mathrm{pH} 6.0,1 \mathrm{mM} \mathrm{NaCl}$ ).

The flow curves of the HyA-hydrogels at various CSA@MNP-contents are shown in Fig. 5. There is no significant change in the flow character of gels with increasing CSA@MNPloading. The upward and downward curves are identical. Thixotropy is not detected under the conditions of measurements. The downward curves were evaluated according to the Binghammodel (Fig. 5). The Bingham yield values $\left(\tau_{\mathrm{B}}\right)$ and the plastic viscosities $\left(\eta_{\mathrm{pl}}\right)$ of all gels (Table 1) coincide within the error of the measurements. This is in good agreement with the expected tendency based on the Einstein-equation [47], since the volume fraction of magnetite particles is extremly low in these hydrogels $(\Phi \leq 0.004)$.

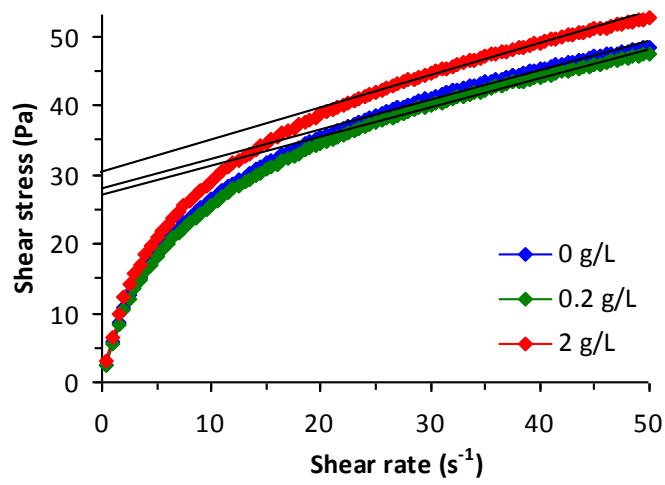

Fig. 5. Effect of CSA@MNP-content on flow curves of HyA-gels (HyA-content: 10 mg/mL, CSA-loading: 0.4 $\mathrm{mmol} / \mathrm{g}, \mathrm{pH} \sim 6.0,1 \mathrm{mM} \mathrm{NaCl}, 25^{\circ} \mathrm{C}$ ). (The upward and downward curves are identical. The equations of fitted Bingham model are marked.)

The viscoelastic properties of gels can be studied under static conditions by creep tests. The measured data of the HyA-gels at different CSA@MNP contents are shown in Fig. 6 at two yield stress values (0.1 and 5.0 Pa). Both the HyA-gel and the magnetic hydrogels show viscous properties at the applied stress values showing that the extent of deformation depends on the applied stress, but it is independent of the magnetite content. 


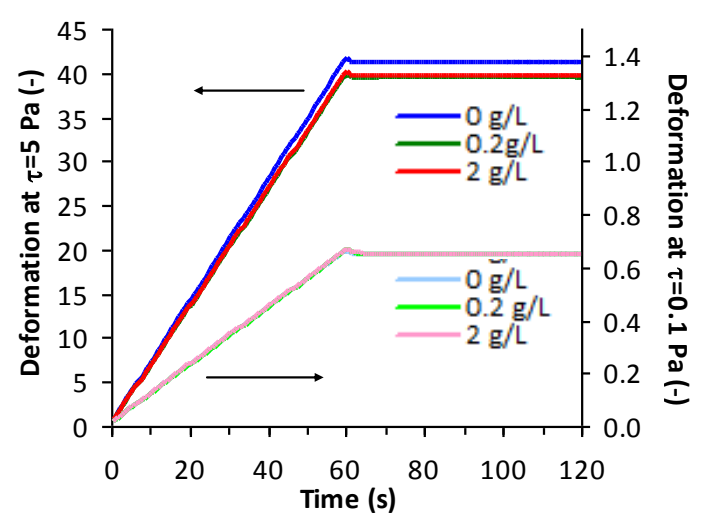

Fig. 6. Creep and recovery test results for HyA-gels at different CSA@MNP-content (HyA-content: $10 \mathrm{mg} / \mathrm{mL}$, CSA-loading: $0.4 \mathrm{mmol} / \mathrm{g}, \mathrm{pH} \sim 6.0,1 \mathrm{mM} \mathrm{NaCl}, 25^{\circ} \mathrm{C}$ ).

The forced oscillation measurements are suitable to study the viscoelastic properties of gels under dynamic conditions. The oscillation tests of the HyA-gels at different CSA@MNPcontents (Fig. 7) show that all the measured parameters are independent from the CSA@MNPcontent within the error of the measurements.

During the oscillation measurements at $1 \mathrm{~Hz}$ (Fig. 7a) the loss modulus (G”) curves of gels are above the storage modulus $\left(\mathrm{G}^{\prime}\right)$ curves in the whole range of stress $(0.1$ to $100 \mathrm{~Pa})$. Thus, under the condition of measurements the hydrogels show viscous properties. However, during frequency sweep measurements at $1 \mathrm{~Pa}$ (Fig. 7b), the viscous loss modulus (G”) and the elastic storage modulus $\left(G^{\prime}\right)$ of gels cross each other. This is characteristic for the viscoelastic nature of HyA, i.e., at lower frequencies (analogous to the static position of the body) the HyAgel behaves as a viscous solution ensuring to hold the skeleton, however, at higher frequencies (analogous to the motion of the joints) the hydrogel behaves elastically allowing an effective lubrication between the cartilages [48-50]. This property is fundamental and essential for the natural synovial fluid. The transition from viscous to elastic behaviour can be characterized by the so-called crossover point (Table 1), which is at $\sim 1.3 \mathrm{~Hz}$ for our magnetic HyA-gels in case of $1 \mathrm{~Pa}$ shear stress.
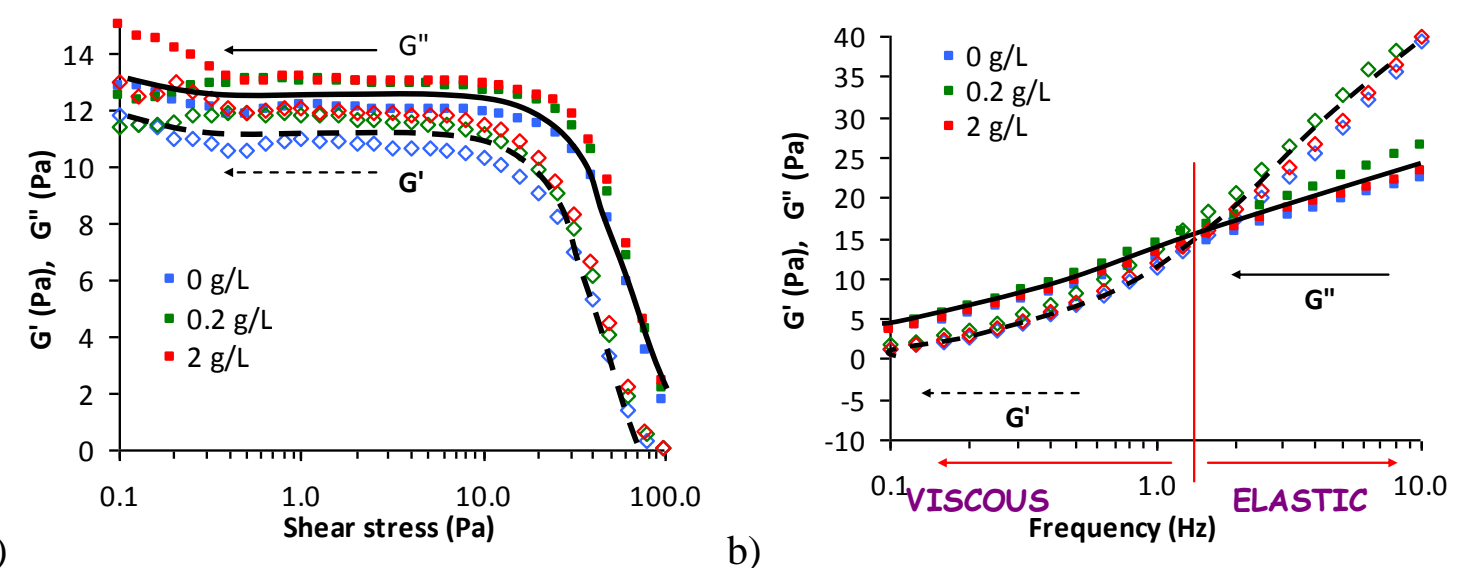

Fig. 7. Forced oscillation tests of HyA-gels at different CSA@MNP-content as a function (a) of shear stress at 1 $\mathrm{Hz}$ and (b) of frequency at $1 \mathrm{~Pa}$. (HyA-content: $10 \mathrm{mg} / \mathrm{mL}$, CSA-loading: $0.4 \mathrm{mmol} / \mathrm{g}, \mathrm{pH}$. 6.0, $1 \mathrm{mM} \mathrm{NaCl}, 25$ ${ }^{\circ} \mathrm{C}$ ). 
Table 1. Summary of the hydrogel's characteristic rheological parameters at different CSA@MNP contents (HyA-content: $10 \mathrm{mg} / \mathrm{mL}$, CSA-loading: $0.4 \mathrm{mmol} / \mathrm{g}, \mathrm{pH} \sim 6.0,1 \mathrm{mM} \mathrm{NaCl}, 25^{\circ} \mathrm{C}$ ).

\begin{tabular}{|c|c|c|c|}
\hline CSA@MNP magnetite content & $0.0 \mathrm{~g} / \mathrm{L}$ & $0.2 \mathrm{~g} / \mathrm{L}$ & $2.0 \mathrm{~g} / \mathrm{L}$ \\
\hline Bingham yield stress $(\mathbf{P a})$ & 28.0 & 27.1 & 30.5 \\
\hline plastic viscosity $(\mathrm{Pa} \cdot \mathbf{s})$ & 0.42 & 0.42 & 0.46 \\
\hline crossover point $(\mathrm{Hz})^{1}$ & 1.3 & 1.1 & 1.4 \\
\hline
\end{tabular}

1 intersection point between the viscous and the elastic behaviour in forced oscillation during the frequency sweep at $1 \mathrm{~Pa}$.

The characteristic rheological parameters of the magnetic HyA-gel loaded with $2 \mathrm{~g} / \mathrm{L}$ CSA@MNP (indicated as HyA + magnetite- $\mathrm{COO}^{-}$) can be compared with those of other HyAbased magnetic hydrogels as shown in Table 2. It can be seen that the values of the different parameters for the listed hydrogels vary significantly, probably because these measurements were made under different conditions, such as temperature, salt concentration, $\mathrm{pH}$, fixed frequency or stress, etc. There were differences even in the rate of cross-linking. Our magnetic hydrogels are not yet cross-linked, however, the un-bound carboxylate groups of both CSA and Hyal (as seen in Fig.1) are prone to react with $\mathrm{Ca}^{2+}$ ions forming a cross-linked structure with tuneable flow properties. The latter will be the subject of our future studies.

Table 2. Characteristic rheological parameters of different HyA-hydrogels.

\begin{tabular}{|c|c|c|c|c|c|c|c|c|}
\hline \multirow[t]{2}{*}{ Hydrogels } & \multirow[t]{2}{*}{$\begin{array}{l}\text { magne- } \\
\text { tic }\end{array}$} & \multirow[t]{2}{*}{$\begin{array}{l}\text { cross- } \\
\text { linked }\end{array}$} & \multicolumn{2}{|c|}{$\begin{array}{l}\text { at linear range } \\
\text { of stress sweep }\end{array}$} & \multicolumn{2}{|c|}{$\begin{array}{l}\text { at crossover } \\
\text { point in } \\
\text { frequency sweep }\end{array}$} & \multicolumn{2}{|c|}{$\begin{array}{l}\text { from flow } \\
\text { curve }\end{array}$} \\
\hline & & & $\begin{array}{c}\mathrm{G}^{\prime} \\
(\mathrm{Pa}) \\
\end{array}$ & $\begin{array}{c}\mathrm{G}^{\prime \prime} \\
(\mathrm{Pa}) \\
\end{array}$ & $\begin{array}{c}\mathrm{f} \\
(\mathrm{Hz})\end{array}$ & $\begin{array}{c}\mathrm{G}^{\prime}=\mathrm{G}^{\prime \prime} \\
(\mathrm{Pa})\end{array}$ & $\begin{array}{c}\tau_{\mathrm{B}} \\
(\mathrm{Pa}) \\
\end{array}$ & $\begin{array}{c}\eta_{\mathrm{pl}} \\
(\mathrm{Pa} \cdot \mathrm{s})\end{array}$ \\
\hline $\mathrm{HyA}+$ magnetite- $\mathrm{COO}^{-1}$ & yes & no & 11 & 13 & 1.4 & 15 & 30 & 0.4 \\
\hline HyA + magnetite $-\mathrm{NH}_{2}[15]^{2}$ & yes & yes & 350 & 25 & - & - & - & - \\
\hline HyA-SH + iron-oxide-COOH [16 ${ }^{3}$ & yes & yes & 510 & - & - & - & - & - \\
\hline HyA $[50]$ & no & no & - & - & 0.02 & 20 & 120 & 0.7 \\
\hline HyA $[50]$ & no & yes & - & - & 0.11 & 20 & 90 & 0.7 \\
\hline HyA Synvisc $[51]^{4}$ & no & yes & 100 & 20 & - & - & - & - \\
\hline
\end{tabular}

${ }^{1}$ magnetite: chondroitin-sulfate-A-coated

2 magnetite: 3-aminopropyl)trimethoxysilane-functionalized

${ }^{3}$ HyA: modified with hydrazide and thiol groups, iron-oxide: oleic acid coated in toluene

${ }^{4}$ commercially available intra-articular injection

\section{Conclusions}

The aim of this work was to prepare novel biocompatible HyA-based magnetic hydrogels using CSA-coated superparamagnetic magnetite nanoparticles and to characterize their aggregation state and rheological properties as well. The solid experimental facts allow us to conclude that HyA-based magnetic hydrogels can be prepared from CSA@MNPs and they remained stable and homogeneously dispersed even after three months of storage. Rheological studies show, that at $\mathrm{pH} 6.0$ and $1 \mathrm{mM} \mathrm{NaCl}$ the behaviour of magnetic hydrogels was appreciably independent from the magnetite content up to $2 \mathrm{~g} / \mathrm{L}$. Further studies are needed at $\mathrm{pH} \sim 7.3,150 \mathrm{mM} \mathrm{NaCl}$ and $37^{\circ} \mathrm{C}$ to approximate the composition of commercial HyA-based intra-articular injections and in vivo conditions. However, the prepared HyA-based magnetic hydrogels are promising candidates for magnetic intra-articular fluid in the treatment of osteoarthritis. By implanting a permanent magnet into the bone in close vicinity of the knee joint for example, the magnetic HyA-gel with increased CSA@MNP content probably can be held at the eroded area. Thus, it is predictable that the necessary distance between the cartilages 
can be provided to reduce the pain during motion and even the requested lubrication can be ensured in the joint for a longer time.

\section{Acknowledgment}

This research was supported by the OTKA (NK 84014) grant as well as by European Union and the State of Hungary, co-financed in the framework of TÁMOP 4.2.4. A/2-11-1-2012-0001 'National Excellence Program'. We thank Erzsébet Csányi (University of Szeged, Department of Pharmaceutical Technology) for rheology measurements.

\section{References}

1 Y. Li, G. Huang, X. Zhang, B. Li, Y. Chen, T. Lu, T.J. Lu, F. Xu, Magnetic Hydrogels and Their Potential Biomedical Applications. Adv. Funct. Mater. 23 (2013) 660-672.

2 N.A. Peppas, P. Bures, W. Leobandung, H. Ichikawa, Hydrogels in pharmaceutical formulations. Eur. J. Pharm. Biopharm. 50 (2000) 27-46.

3 D. Gao, H. Xu, M. A. Philbert, R. Kopelman, Bioeliminable nanohydrogels for drug delivery. Nano Lett. 8 (2008) 3320-3324.

4 G.D. Nicodemus, S.J. Bryant, Cell encapsulation in biodegradable hydrogels for tissue engineering applications. Tissue Eng., Part B 14 (2008) 149-165.

$5 \quad$ S. Ladet, L. David, A. Domard, Multi-membrane hydrogels. Nature 452 (2008) 76-79.

6 J. Kost, J. Wolfrum, R. Langer, Magnetically enhanced insulin release in diabetic rats. J. Biomed. Mater. Res. 21 (1987) 1367-1373.

7 V.M. De Paoli, S.H. De Paoli Lacerda, L. Spinu B. Ingber, Z. Rosenzweig, N. Rosenzweig, Effect of an oscillating magnetic field on the release properties of magnetic collagen gels. Langmuir 22 (2006) 5894-5899.

8 M. Arruebo, R. Fernández-Pacheco, M.R. Ibarra, J. Santamaría, Magnetic nanoparticles for drug delivery. Nano Today 2 (2007) 22-32.

9 M.H. Liao, D.H. Chen, Immobilization of yeast alcohol deshydrogenase on magnetic nanoparticles. Biotechnol. Lett. 23 (2001) 1723-1727.

10 G. Bayramoglu, B. Altintas, M.Y. Arica, Immobilization of glucoamylase onto polyaniline-grafted magnetic hydrogel via adsorption and adsorption/cross-linking. Appl. Microbiol. Biotechnol. 97 (2013) 1149-1159.

11 L.L. Lao, R.V. Ramanujan, Magnetic and hydrogel composite materials for hyperthermia applications. J. Mater. Sci.: Mater. Med. 15 (2004) 1061-1064.

12 A.L. Daniel-da-Silva, S. Fateixa, A.J. Guiomar, B.F. Costa, N.J. Silva, T. Trindade, B.J. Goodfellow, A.M. Gil, Biofunctionalized magnetic hydrogel nanospheres of magnetite and kappa-carrageenan. Nanotechnology 20 (2009) 355602.

13 Y. Wang, B. Li, Y. Zhou, D. Jia, In Situ Mineralization of Magnetite Nanoparticles in Chitosan Hydrogel. Nanoscale Res. Lett. 4 (2009) 1041-1046.

14 D. Zhang, P. Sun, P. Li, A. Xue, X. Zhang, H. Zhang, X. Jin, A magnetic chitosan hydrogel for sustained and prolonged delivery of Bacillus Calmette-Guérin in the treatment of bladder cancer. Biomaterials 34 (2013) 10258e10266.

15 R. Barbucci, G. Giani, S. Fedi, S. Bottari, M. Casolaro, Biohydrogels with magnetic nanoparticles as crosslinker: Characteristics and potential use for controlled antitumor drug-delivery. Acta Biomater. 8 (2012) 4244-4252.

16 Y. Zhang, Y. Sun, X. Yang, J. Hilborn, A. Heerschap, D. A. Ossipov, Injectable In Situ Forming Hybrid Iron Oxide-Hyaluronic Acid Hydrogel for Magnetic Resonance Imaging and Drug Delivery. Macromol. Biosci.14 (2014) 1249-1259. 
17 J. Li, Y. He, W. Sun, Y. Luo, H. Cai, Y. Pan, M. Shen, J, Xia, X. Shi, Hyaluronic acidmodified hydrothermally synthesized iron oxide nanoparticles for targeted tumor MR imaging, Biomaterials 35 (2014) 3666-3677.

18 M. Babic, D. Horak, P. Jendelova, V. Herynek, V. Proks, V. Vanecek, P. Lesn, E. Sykova, The use of dopamine-hyaluronate associatecoated maghemite nanoparticles to label cells. In. J. Nanomed. 7 (2012) 1461-1474.

19 Y. Lee, H. Lee, Y.B. Kim, J. Kim, T. Hyeon, H. Park, P.B. Messersmith, T.G. Park, Bioinspired Surface Immobilization of Hyaluronic Acid on Monodisperse Magnetite Nanocrystals for Targeted Cancer Imaging, Adv. Mater. 20 (2008) 4154-4157.

20 E. Tombácz, I.Y. Tóth, D. Nesztor, E. Illés, A. Hajdú, M. Szekeres, L. Vékás, Adsorption of organic acids on magnetite nanoparticles, $\mathrm{pH}$-dependent colloidal stability and salt tolerance. Coll. Surf. A 435 (2013) 91-96.

21 M. Szekeres, I.Y. Tóth, E. Illés, A. Hajdú, I. Zupkó, K. Farkas, G. Oszlánczi, L. Tiszlavicz, E. Tombácz, Chemical and colloidal stability of carboxylated core-shell magnetite nanoparticles designed for biomedical applications. Int. J. Mol. Sci. 14 (2013) 14550-14574.

22 E. Tombácz, M. Szekeres, A. Hajdú, I.Y. Tóth, R.A. Bauer, D. Nesztor, E. Illés, I. Zupkó, L. Vékás, Colloidal stability of carboxylated iron oxide nanomagnets for biomedical use. Period. Polytech-chem. 58 (2014) 3-10.

23 A. Hajdú, M. Szekeres, I.Y. Tóth, R.A. Bauer, J. Mihály, I. Zupkó, E. Tombácz, Enhanced stability of polyacrylate-coated magnetite nanoparticles in biorelevant media. Coll. Surf. B 94 (2012) 242-249.

24 I.Y. Tóth, E. Illés, R.A. Bauer, D. Nesztor, M. Szekeres, I. Zupkó, E. Tombácz, Designed polyelectrolyte shell on magnetite nanocore for dilution-resistant biocompatible magnetic fluids. Langmuir 28 (2012) 16638-16646.

25 I.Y. Tóth, E. Illés, M. Szekeres, E. Tombácz, Preparation and characterization of chondroitin-sulfate-A-coated magnetite nanoparticles for biomedical applications

26 D.H. Neustadt, Intra-articular injections for osteoarthritis of the knee. Clev. Clin. J. Med. 73 (2006) 897-911.

27 C. Carulli, F. Matassi, R. Civinini, M. Morfini, M. Tani, M. Innocenti, Intra-articular injections of hyaluronic acid induce positive clinical effects in knees of patients affected by haemophilic arthropathy. Knee 20 (2013) 36-39.

28 O. Namiki, H. Toyoshima, N. Morisaki, Therapeutic effect of intra-articular injection of high molecular weight híaluronic acid on osteoarthritis of the knee. Int. J. Clin. Pharmacol. Ther. Toxicol. 20 (1982) 501-507.

29 K.D. Brandt, G.N. Smith, L.S. Simon, Intraarticular injection of hyaluronan as treatement. Arthritis Rheum. 43 (2000) 1192-1203.

30 J.O. Printz, J.J. Lee, M. Knesek, A.G. Urquhart, Conflict of Interest in the Assessment of Hyaluronic Acid Injections for Osteoarthritis of the Knee: An Updated Systematic Review. J. Arthroplasty 28 (2013) 30-33.

31 J. Schiller, N. Volpi, E. Hrabárová, L. Soltés, Hyaluronic acid: a natural biopolymer. In: S. Kalia, L. Avérous (Eds.), Biopolymers: biomedical and environmental applications. Hoboken, NJ, USA, John Wiley \& Sons, 2011.

32 E. Illés, E. Tombácz, The role of variable surface charge and surface complexation in the adsorption of humic acid on magnetite. Coll. Surf. A 230 (2006) 99-109.

33 E. Illés, E. Tombácz, The effect of humic acid adsorption on pH-dependent surface charging and aggregation of magnetite nanoparticles. J. Colloid Interface Sci. 295 (2006) 115-123. 
34 L. Vékás, D. Bica, O. Marinica, Magnetic nanofluids stabilized with various chain length surfactants. Rom. Rep. Phys. 58 (2006) 217-228.

35 D. Bica, L. Vékás, M.V. Avdeev, O. Marinica, V. Socoliuc, M. Balasoiu, V.M. Garamus, Sterically stabilized water based magnetic fluids: Synthesis, structure and properties. J. Magn. Magn. Mater. 311 (2007) 17-21.

36 E. Tombácz, E. Illés, A. Majzik, A. Hajdú, N. Rideg, M. Szekeres, Ageing in the inorganic nanoworld: Example of magnetite nanoparticles in aqueous medium. Croat. Chem. Acta 80 (2007) 503-515.

37 R.M. Cornell, U. Schwertmann, The Iron Oxides. Structure, Properties, Reactions, Occurrence and Uses. VCH, Weinheim, 1996.

38 M. Bathe, G.C. Rutledge, A.J. Grodzinsky, B. Tidor, A Coarse-Grained Molecular Model for Glycosaminoglycans: Application to Chondroitin, Chondroitin Sulfate, and Hyaluronic Acid. Biophys. J. 88 (2005) 3870-3887.

39 R.L. Cleland, Electrophoretic mobility of wormlike chains. I. Experiment: hyaluronate and chondroitin 4-sulfate. Macromolecules 24 (2010) 4386-4390.

40 H. Wang, D. Loganathan, R.J. Linhardt, Determination of the $\mathrm{pK}_{\mathrm{a}}$ of glucuronic acid and the carboxy groups of heparin by ${ }^{13} \mathrm{C}$-nuclear-magnetic-resonance spectroscopy. Biochem. J. 278 (1991) 689-695.

41 K.J. Grande-Allen, N. Osman, M.L. Ballinger, H. Dadlani, S. Marasco, P.J. Little, Glycosaminoglycan synthesis and structure as targets for the prevention of calcific aortic valve disease. Cardiovasc. Res. 76 (2007) 19-28.

42 H.A. Barnes, J.F. Hutton, K. Walters, An Introduction to Rheology. Elsevier, Amsterdam, 1989.

43 A. Majzik, E. Tombácz, Interaction between humic acid and montmorillonite in the presence of calcium ions II. Colloidal interactions: Charge state, dispersing and/or aggregation of particles in suspension. Org. Geochem. 38 (2007) 1330-1340.

44 J.M. Bigham, R.W. Fritzpatrick, D.G. Schulze, In: J.B. Dixon, D.G. Schulze (Eds.), Soil Mineralogy with Environmental Applications. SSSA, Madison, 2002.

45 E. Tombácz, Adsorption from Electrolyte Solutions. In: J. Tóth, (Ed.) Adsorption: Theory, Modeling and Analysis. Marcel Dekker, New York, 2002.

46 G. Sposito, Characterization of Particle Surface Charge. In: J. Buffle, H.P. van Leeuwen (Eds.), Environmental Particles. Lewis, Boca Raton, 1992.

47 A. Einstein, Eine neue Bestimmung der Moleküldimensionen. Annalen der Physik 19 (1906) 289-306.

48 E.A. Balazs, The physical properties of synovial fluid and the special role of hyaluronic acid. In: A. Helfet (Ed.), Disorders of the knee. Philadelphia: T.B. Lippincott Company, 1974.

49 M.K. Cowman, S. Matsuoka, Experimental approaches to hyaluronan structure. Carbohydr. Res. 340 (2005) 791-809.

50 Sz. Berkó, M. Maroda, M. Bodnár, G. Erős, P. Hartmann, K. Szentner, P. Szabó-Révész, L. Kemény, J. Borbély, E. Csányi, Advantages of cross-linked versus linear hyaluronic acid for semisolid skin delivery systems. Eur. Polym. J. 49 (2013) 511-2517.

51 P. Mathieu, T. Conrozier, E. Vignon, Y. Rozand, M. Rinaudo, Rheologic Behavior of Osteoarthritic Synovial Fluid after Addition of Hyaluronic Acid, Clin Orthop Relat Res. 467 (2009) 3002-3009. 